\title{
O papel da clorofila na alimentação humana: uma revisão
}

\author{
Ursula Maria Lanfer-Marquez
}

Departamento de Alimentos e Nutrição Experimental, Faculdade de Ciências Farmacêuticas, Universidade de São Paulo

Correspondência:

U. M. Lanfer-Marquez

Departamento de Alimentos e

Nutrição Experimental

FCF-USP

Av. Prof. Lineu Prestes, 580

Cidade Universitária - Bloco 14

05508-900 - São Paulo - Brasil

E-mail: lanferum@usp.br
Os eventuais efeitos biológicos benéficos da clorofila, presente em alimentos, suscitam polêmica e dúvidas entre os consumidores. As informações divulgadas nos meios de comunicação que atribuem à molécula da clorofila numerosos efeitos terapêticos, quase miraculosos, se contrapõem à falta de aprovação dessas atribuições pela comunidade cientifica. Tornar disponiveis os resultados das pesquisas mais recentes sobre o assunto e analisar criticamente esses dados foi o objetivo desta revisão. São discutidos os mecanismos de degradação da clorofila durante a senescência, armazenamento e processamento de vegetais, bem como no processo digestivo, considerando que os produtos de degradação podem diferir em cada caso. Avalia-se a importância da modificação estrutural da clorofila tendo em vista possiveis atividades antioxidantes, antimutagênicas e quimiopreventivas. Infelizmente, não há evidências fortes o suficiente que possam ser consideradas conclusivas quanto ao retardo ou prevenção de doenças pela clorofila. Contudo, a variedade de hipóteses, embora algumas muito distantes de serem comprovadas em humanos, levantam estratégias para dar continuidade às investigacões. Sugere-se, ainda, que sejam conduzidos estudos relativos à atividade biológica do fitol, uma vez que existem evidências que esta molécula, na sua forma livre, pode ser absorvida para a corrente sanguinea e exercer importantes funções no metabolismo lipídico e na regulação de processos metabólicos.
Unitermos:

- Clorofila

- Alimentação humana

- Degradação

- Absorção

- Efeitos biológicos

- Fitol

\section{INTRODUÇÃO}

Até alguns anos atrás poucos eram os profissionais da Saúde que se preocupavam com o efeito biológico que a clorofila poderia exercer quando ingerida juntamente com a dieta. As clorofilas eram consideradas apenas como os pigmentos responsáveis pela cor verde de plantas, algas e bactérias, tendo como função primordial captar a luz solar para produzir glicose e oxigênio através do processo de fotossíntese, estabelecendo assim o elo para a cadeia alimentar.

Por outro lado, a ingestão de vegetais verdes é considerada saudável e este hábito vem sendo incorporado cada vez mais ao estilo de vida moderna, visando ao Bem- 
Estar e à Promoção da Saúde. É moeda corrente na literatura associar a ingestão de frutos e outras partes vegetais a um menor risco de desenvolvimento de doenças, tais como o câncer e doenças cardiovasculares.

Infelizmente, os trabalhos científicos que relatam efeitos benéficos à saúde humana trazidos pela ingestão de vegetais foram realizados com extratos vegetais e não com a clorofila isolada e a escassez de investigações mais aprofundadas com a clorofila em si deve ser atribuída, ao menos parcialmente, à reduzida estabilidade química dessa substância. A instabilidade da clorofila frente a ácidos, calor e luz é bem documentada na literatura (GauthierJaques et al., 2001; Schwartz, Lorenzo, 1990).

O propósito desta breve revisão da literatura é fornecer informações e inferir sobre os eventuais efeitos biológicos que podem advir da ingestão da clorofila, tomando como ponto de partida para a discussão, os anúncios e a propaganda, que vêm sendo veiculados pela mídia, atribuindo à clorofila benefícios sobre praticamente todos os tecidos, órgãos e sistemas do organismo humano, especialmente no que diz respeito à prevenção de doenças coronarianas, de certos tipos de cânceres, diabetes e catarata.

\section{Alimentos funcionais}

Atribui-se a muitos alimentos, além da sua função primordial de suprir o organismo de nutrientes, outras funções dinâmicas, promotoras de saúde. Em 1984, foi proposto o termo "alimento funcional", quando as pesquisas científicas apontavam para essa nova função que os alimentos poderiam apresentar. Reconheceu-se que a dieta e certos hábitos alimentares saudáveis, aliados a esquemas de exercícios físicos, poderiam ter impacto sobre o estado de saúde da população, especialmente em idosos. Entende-se, assim, que os alimentos funcionais se situam numa categoria entre os alimentos convencionais e os medicamentos, devendo ser entendidos como coadjuvantes na prevenção de doenças, mas não na cura ou tratamento de uma disfunção em estágio de desenvolvimento (Arai, 1996)

Desde então, pesquisas ao redor do mundo inteiro vêm sendo realizadas com o intuito de conhecer a miríade de substâncias bioativas nos alimentos, identificar a sua variabilidade e estabilidade durante o processamento e armazenamento, bem como dar suporte científico para o reconhecimento das alegações de propriedades funcionais (Van Duyn, Pivonka, 2000). É essencial, também, a regulamentação pelas autoridades competentes, criando padrões de identidade e de qualidade visando à proteção do consumidor (Lajolo, 2002). Estes alimentos, com regulamentação já aprovada no Japão pelo Ministério da Saúde e Bem-Estar, são denominados de FOSHU (Foods for Specific Health Uses) (Arai, 1996).

Mais de 12000 substâncias naturais com alguma atividade biológica (antibiótica, hormonal, antioxidante, quimiopreventiva, imunológica, entre outras) já foram identificadas em alimentos vegetais (National Research Council,1996). Estas podem ser denominadas de substâncias fitoquímicas, para ressaltar a sua origem vegetal, e suscitam enorme interesse entre os pesquisadores, na tentativa de correlacionar a sua presença com o fato de pessoas habituadas a uma alimentação predominantemente vegetal, aparentemente, apresentarem menores riscos de desenvolver doenças crônico-degenerativas do que aquelas com hábitos alimentares onívoras (Liu et al., 2000; Steinmetz, Potter, 1996; Van Duyn, Pivonka, 2000; Verschuren, 2002).

Estudos realizados com substâncias antioxidantes presentes na dieta demonstraram que é possível diminuir o risco de diversas doenças, como certos tipos de câncer, aterosclerose, artrite reumatóide, redução do sistema imunológico, entre outras, devido à remoção ou ao impedimento da formação de radicais livres e de espécies reativas do oxigênio, que danificam enzimas mitocondriais, membranas plasmáticas e o próprio DNA (Gordon, 1996). Entre os compostos antioxidantes mais conhecidos estão o ácido ascórbico, os tocoferóis, os carotenóides, bem como uma série de compostos fenólicos e polifenólicos, todos eles comumente encontrados em vegetais. Contudo, essas substâncias antioxidantes parecem atuar em sistemas biológicos de uma forma coordenada, ao produzir uma proteção contra o estresse oxidativo. Difícil mesmo é explicar a quem atribuir essa atividade biológica, se à presença de substâncias antioxidantes, a outros componentes da dieta, ou mesmo aos hábitos de vida, uma vez que diversos estudos epidemiológicos falharam, quando se procurava evidenciar os benefícios dessas substâncias, isoladamente (Kitts, 1997). Quando em altas concentrações, tanto o tocoferol (vitamina E) como o betacaroteno podem até exibir atividade pró-oxidante em sistemas modelo in vitro (Gordon 1996).

As substâncias anticarcinogênicas inibem a iniciação, ou a promoção da carcinogênese e podem ser divididas em dois grandes grupos: nutrientes (fibra, vitaminas e minerais) e não-nutrientes, que compreendem os metabólitos secundários (glicosinolatos, sulfetos, flavonóides, fitoestrógenos, isotiocianatos, fenóis, taninos, terpenos e outras). Essas substâncias não são encontradas concomitantemente em todos os vegetais, mas podem estar distribuídas em certas famílias, gêneros, ou até em certas espécies vegetais, com predominância de uma ou outra substância apenas (Rafter, 2002). Apesar da va- 
riedade de mecanismos apontados e do grande número de publicações científicas a respeito, estamos longe, ainda, de entender e de comprovar todo o potencial e a extensão de efeitos biológicos advindos da alimentação.

Ao contrário da maioria das substâncias fitoquímicas, que são encontradas nos vegetais comestíveis em concentrações insuficientes para resultar em algum efeito biológico mensurável, a clorofila é encontrada em quantidades elevadas. $\mathrm{O}$ espinafre, por exemplo, contém ao redor de $150 \mathrm{mg}$ por $100 \mathrm{~g}$ de folhas frescas (Gross, 1991). Na pirâmide dos alimentos, recomenda-se a ingestão de 3 a 5 porções de hortaliças e frutas por dia (Philippi et al., 1999) e, por conseqüência, não faltam divulgações nos meios de comunicação de que grande parte dos benefícios para a saúde humana poderia ser atribuída então à clorofila.

Apesar da lógica desse raciocínio, existem poucos trabalhos científicos que relacionam a ingestão de clorofila com algum efeito benéfico sobre a saúde humana, embora o assunto não seja recente. Os primeiros estudos foram publicados há quase 50 anos relatando efeitos antiinflamatórios, desodorantes, além de atividade eritropoiética e anti-hipertensiva, pela ingestão da clorofila (Kephart, 1955).

Desde então, os estudos publicados atribuem atividades antioxidante, antimutagênica e anticarcinogênica a extratos vegetais, tanto in vitro como in vivo, embora não existam provas concludentes, até o momento, de que a clorofila ou seus derivados realmente estejam envolvidos com a inibição ou retardo de doenças crônico-degenerativas (Botting et al., 1999; Lai et al., 1980; Negishi, 1989; Odin, 1997; Terwel, Van der Hoeven, 1985; Yen et al., 2001).

A nosso ver, uma estratégia inicial de abordagem da questão seria avaliar a que atribuir a ação benéfica porventura existente, se ao vegetal no seu todo, ou apenas à clorofila, e se:

1) a clorofila é uma substância ativa que atua por si só, ou induz a ação de outras substâncias endógenas.

2) a clorofila é uma substância inativa, precursora, podendo ser transformada em substância ativa.

3) a clorofila é ativa em estágio pré-absortivo, ou pósabsortivo, supondo-se que ocorra a efetiva absorção no trato gastro-intestinal.

Para responder a essas questões, acreditamos ser importante conhecer primeiramente a estrutura química e os mecanismos propostos para explicar a degradação da clorofila em vegetais e a partir daí, com base em evidências científicas, inferir sobre as possíveis alterações da molécula, durante o preparo do alimento e após a sua ingestão por humanos ou animais.
O conjunto destes conhecimentos tornar-se-á importante para apontar as possíveis contribuições da ingestão da clorofila sobre a saúde humana. Passaremos a discutir, apesar de brevemente, sobre cada um desses aspectos.

\section{Estrutura química da clorofila}

Quimicamente, a clorofila não é uma molécula isolada, mas compreende uma família de substâncias semelhantes entre si, designadas de clorofila $\boldsymbol{a}, \boldsymbol{b}, \boldsymbol{c}$ e $\boldsymbol{d}$. Estruturalmente são moléculas complexas, pertencentes à classe das porfirinas, formadas por 4 anéis pirrólicos e um quinto anel isocíclico, localizado ao lado do terceiro anel pirrólico. Os anéis estão ligados entre si por pontes metilênicas e a molécula contém um átomo de magnésio no seu interior, coordenado aos anéis. No quarto anel pirrólico, o ácido propiônico ali existente é esterificado por um álcool acíclico de cadeia longa, geralmente o fitol, conferindo à clorofila um caráter hidrofóbico (Gross, 1991; Rüdiger, Schoch, 1988).

A clorofila $\boldsymbol{a}$, a mais abundante e a mais importante dessa família, corresponde a aproximadamente $75 \%$ dos pigmentos verdes encontrados nos vegetais (Gross, 1991). A clorofila $\boldsymbol{b}$ difere da clorofila $\boldsymbol{a}$ por uma pequena variação na substituição no anel pirrólico II. As clorofilas $\boldsymbol{c}$ e $\boldsymbol{d}$ são encontradas em algas (Schwartz, Lorenzo, 1990). Uma representação da molécula da clorofila $\boldsymbol{a}$ pode ser observada na Figura 1.

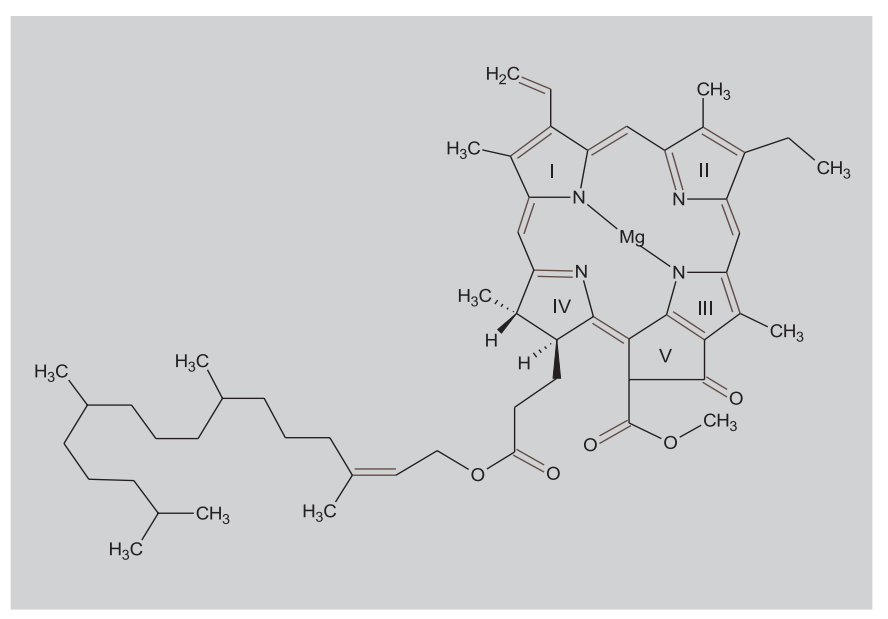

FIGURA 1 - Estrutura química da clorofila a.

\section{Degradação da clorofila em vegetais senescentes}

Estima-se que $10^{9}$ ton de clorofila são sintetizadas e degradadas por ano durante o fenômeno natural da mudança da cor das folhas durante o outono, especialmente nos países do hemisfério Norte, e também durante o amadurecimento de frutos. Mas até 1987, o processo de degrada- 
ção em vegetais senescentes era considerado um "enigma biológico" (Hendry et al., 1987). A partir de então, significativos progressos para a elucidação dos mecanismos de degradação foram alcançados e sugeriram-se dois tipos de reações: Tipo I, envolvendo a perda do fitol, do $\mathrm{Mg}^{2+} \mathrm{e}$ outras modificações das cadeias laterais da molécula. As reações do Tipo II correspondem a fragmentação oxidativa do anel tetrapirrólico (Shioi et al., 1995).

Todo o processo parece ter início com a ação de duas enzimas, a clorofilase e a $\mathrm{Mg}$-dequelatase, que removem o fitol e o $\mathrm{Mg}^{2+}$, respectivamente, formando clorofilídeos e feofitinas, embora não esteja clara a ordem em que essas reações ocorrem; acredita-se que além da ação das enzimas, fatores não-enzimáticos também possam estar envolvidos (Amir-Shapira et al., 1987; Heaton, Marangoni, 1996; Heaton et al., 1996). Supõe-se que esse processo seja extremamente rápido, considerando as propriedades fotodinâmicas da molécula e a catálise enzimática. A coloração dos clorofilídeos é semelhante à da clorofila original, enquanto as feofitinas e os feoforbídeos, que são os produtos resultantes da ação da Mg-dequelatase sobre as clorofilas e os clorofilídeos, respectivamente, apresentam uma cor verde tendendo ao marrom, deduzindo-se que a remoção do átomo de $\mathrm{Mg}$ é fundamental para a mudança de cor (Langmeier et al., 1993).

No entanto, como já foi demonstrado em pesquisas utilizando marcação com isótopos, o passo fundamental, responsável pela perda total da cor, corresponde à abertura do anel tetrapirrólico com introdução de um átomo de oxigênio, por intermédio de um processo co-oxidativo, catalizado por uma enzima, a feoforbídeo a monooxigenase (Curty et al., 1995; Rüdiger, 1997). Este processo foi confirmado posteriormente por Hörtensteiner et al. (1998) e Matile et al. (1999). Os produtos primários da ação dessa enzima são compostos incolores, fluorescentes, que são rapidamente transformados em catabólitos não-fluorescentes de estruturas químicas ainda pouco elucidadas (Oberhuber et al., 2001; Oberhuber, Kräutler, 2002; Takamiya et al., 2000; Wüthrich et al., 2000). Aparentemente, outras enzimas oxidativas, tais como a peroxidase, e a lipoxigenase também podem contribuir com a descoloração da clorofila (Johnson-Flanagan, Spencer, 1996; Martinez et al., 2001). A Figura 2 ilustra o processo de degradação da clorofila $\boldsymbol{a}$ pela ação de enzimas que atuam durante a maturação ou senescência do vegetal.

\section{Efeitos do processamento sobre a degradação da clorofila}

Ao contrário dos mecanismos predominantemente enzimáticos que atuam nos vegetais senescentes ou duran- te o armazenamento de vegetais frescos, diversas outras reações de degradação da clorofila ocorrem durante o processamento. As reações enzimáticas costumam conferir coloração amarronzada ao vegetal, atribuída, ao menos parcialmente, à formação de feofitinas e feoforbídeos, levando o consumidor à rejeição do produto (Heaton et al.,1996b). Já durante o pré-processamento industrial, a desintegração de estruturas celulares promove a exposição da clorofila tornando-a suscetível a diversas reações enzimáticas e não-enzimáticas, que também conferem ao vegetal uma coloração indesejável. Da mesma forma, o estádio de maturação e as condições de armazenamento pós-colheita de grãos de soja e outras sementes oleaginosas, interferem significativamente com os teores de clorofila, cuja presença é considerada um fator depreciador da qualidade dos grãos (Gomes et al., 2003). A fermentação de azeitonas verdes pode resultar em defitilação enzimática (Minguez-Mosquera et al., 1994). As pesquisas têm demonstrado que algumas enzimas como clorofilase, feoforbídeo a mono-oxigenase, hidrolases lipolíticas e lipoxigenases podem atuar conjuntamente levando à degradação da clorofila (Martinez et al., 2001). Ácidos graxos liberados por hidrolases podem ser oxidados por lipoxigenases e produzir hidroperóxidos. Os radicais livres provenientes da degradação desses hidroperóxidos são potencialmente danosos para a clorofila (Funamoto et al., 2002; Gauthier-Jaques et al., 2001; Yamauchi, Watada, 1991).

Por outro lado, durante o processamento térmico, a principal via de degradação é a substituição do átomo de $\mathrm{Mg}$ por dois átomos de $\mathrm{H}$, processo conhecido por feofitinização, além de poder ocorrer também uma epimerização. Neste caso a reação não é catalisada enzimaticamente e, sim, pela acidez do meio que favorece a perda do $\mathrm{Mg}^{2+}$. As feofitinas possuem coloração próxima ao verde oliva e estão sujeitas a hidrólise química, que resulta na liberação da molécula do fitol, produzindo um feoforbídeo hidrossolúvel. Observou-se que o tratamento térmico prolongado e a produção de enlatados pode resultar também na perda do grupo metilcarboxila havendo formação de pirofeofitinas (Heaton et al., 1996a; Schwartz, Lorenzo, 1991; Teng, Cheng, 1999).

A desidratação de vegetais, usados com freqüência como ingredientes em sopas instantâneas, condimentos e outros alimentos secos, costuma levar a uma dramática perda da clorofila e concomitante aumento na concentração de feofitinas. Esta mudança de coloração aumenta com a temperatura empregada, sendo acompanhada por um decréscimo do $\mathrm{pH}$ natural do vegetal pela liberação de ácidos orgânicos celulares, criando as condições favoráveis para a feofitinização. Contudo, o branqueamento pré- 

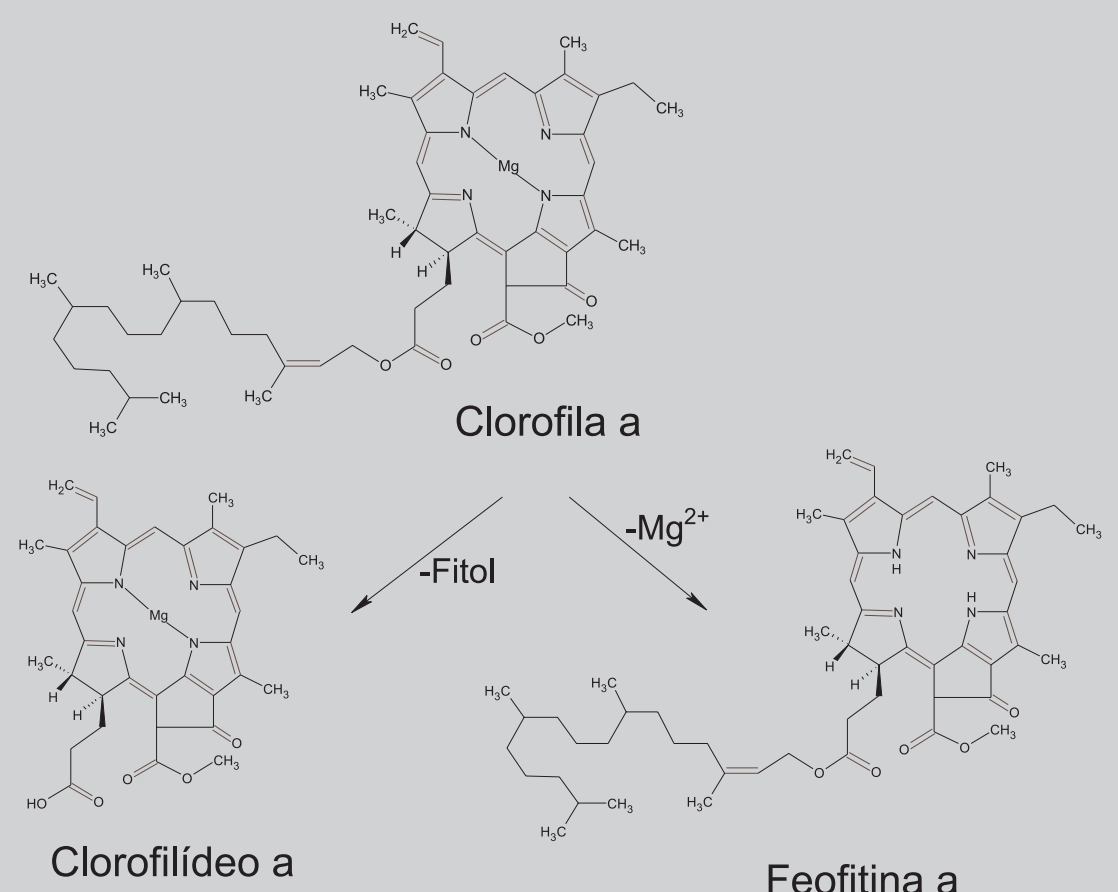

Feofitina a

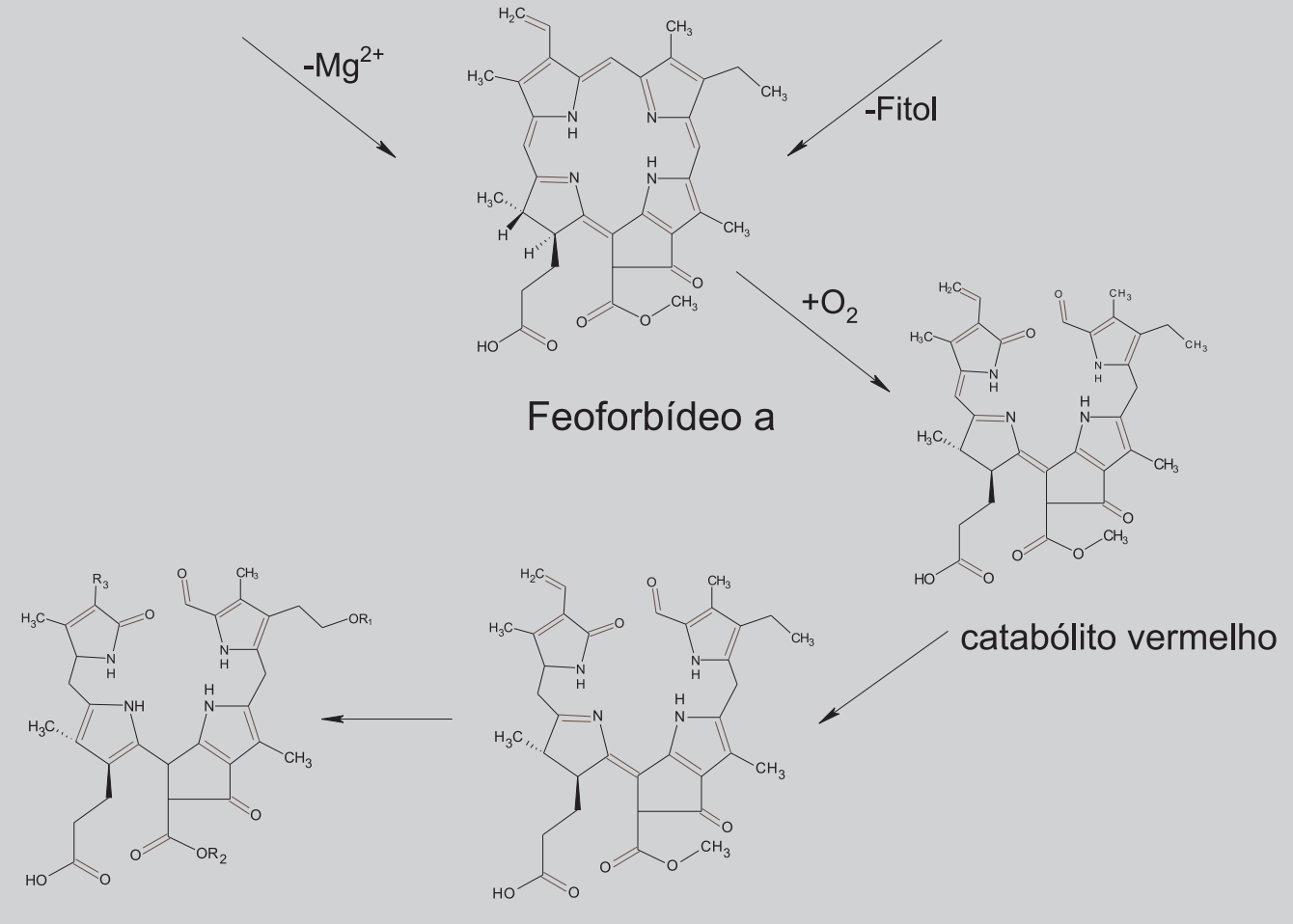

catabólito incolor não-fluorescente

\section{catabólito fluorescente}

FIGURA 2 - Etapas da degradação da clorofila e estruturas moleculares de seus principais catabólitos.

vio desses vegetais em meio neutro ou alcalino e o emprego de processamento a altas temperaturas por tempos muito curtos (HTST - High Temperature Short Time), têm sido úteis na retenção de maior quantidade de pigmento.
Porém, a perda da cor observada posteriormente ao processamento, durante o armazenamento, independente do $\mathrm{pH}$, tem sido atribuída a outras vias de degradação (Maharaj, Sankat, 1996). Os parâmetros mais importantes 
são: tempo e temperatura de secagem e o pré-tratamento aos quais os vegetais são submetidos (branqueamento, emprego de agentes sulfitantes e congelamento), ressaltando-se que a velocidade e a via de degradação podem variar em função do vegetal (Heaton, Marangoni, 1996; Minguez-Mosquera et al., 1989). Vegetais enlatados costumam ter praticamente toda a clorofila degradada para feofitina e pirofeofitina durante um aquecimento severo, imperioso para atingir a esterilidade comercial (Schwartz, Lorenzo, 1991). Uma generalização pode ser feita afirmando que, quanto menor a temperatura de processamento, menor será a taxa de degradação da clorofila (Rocha et al., 1993).

Não faltaram esforços para preservar a coloração verde de vegetais processados. Além dos agentes alcalinizantes, tais como $\mathrm{Mg}(\mathrm{OH})_{2}$ e $\mathrm{Zn}(\mathrm{OH})_{2}$, utilizados para elevar o $\mathrm{pH}$, o emprego de HTST, o tratamento térmico com vapor de água e a transformação enzimática da clorofila em clorofilídeo, não são efetivos para garantir a estabilidade da coloração verde durante o período de armazenamento de vegetais processados.

A formação de complexos espontâneos entre átomos metálicos e a clorofila e seus derivados durante $\mathrm{o}$ processamento, fenômeno esse conhecido como reverdescimento, foi descoberto por acaso, em 1943, por Fischbach e atribuído à formação de um complexo com zinco ou com cobre que possuía uma cor verde brilhante e estável. Essa descoberta foi o marco para o início do desenvolvimento tecnológico, que resultou na aprovação em alguns países, incluindo o Brasil, de dois corantes comerciais, conhecidos por clorofila e clorofilina cúpricas, na forma de sal de sódio, potássio, ou de amônio. O cobre forma complexos mais rapidamente do que o zinco, mas o uso de complexos com zinco é preferível devido à natureza tóxica dos íons $\mathrm{Cu}^{2+}$ (LaBorde, Von Elbe, 1994).

\section{Degradação da clorofila após a ingestão por animais}

Ma e Dolphin (1999), em sua revisão sobre o assunto, encontraram evidências que a maior parte da clorofila $\boldsymbol{a}$ ingerida por herbívoros ou animais aquáticos, que se alimentam de algas, está presente no intestino desses animais com o macrociclo pirrólico intacto, embora apresente diversas modificações nos grupos periféricos da molécula. Este fato confirma o que já havia sido descrito em 1968, por Baxter, de que 90 a $95 \%$ da radioatividade de feofitina marcada com ${ }^{14} \mathrm{C}$ e ingerida por indivíduos normais ou por pacientes com síndrome de Refsum, pode ser recuperada nas fezes.

O meio ácido do estômago favorece a feofitinização, que corresponde à remoção do átomo de $\mathrm{Mg}$, como já descrito anteriormente. $\mathrm{O}$ estudo de Ferruzzi e colaboradores (2001) comprova que $95 \%$ da clorofila é totalmente convertida em feofitina empregando uma simulação de digestão gástrica incubando um purê de espinafre em $\mathrm{pH}$ 2,0 , durante 1 hora a $37^{\circ} \mathrm{C}$. Vale ressaltar que a liberação do $\mathrm{Mg}^{2+}$, a partir da clorofila, é altamente dependente do $\mathrm{pH}$ e de diversos fatores biológicos, de difícil controle. A idade, condição fisiológica, efeito tampão e ação de certos medicamentos atuam sobre o pH gástrico. De fato, os pesquisadores mencionados observaram uma feofitinização muito reduzida em pH 4,0 e em pH 6,0, a clorofila se mostrou estável durante 1 hora de incubação a $37^{\circ} \mathrm{C}$.

De qualquer forma, $\mathrm{o} \mathrm{Mg}^{2+}$ liberado durante esse processo pode ser absorvido pelo organismo animal, contribuindo com as necessidades diárias desse mineral. O $\mathrm{Mg}^{2+}$ está envolvido, além das funções estruturais, com inúmeras reações metabólicas essenciais: transporte de íons, síntese de outras moléculas essenciais, cofator de inúmeras enzimas e produção de energia. Mais de $60 \%$ do magnésio no corpo humano é encontrado no esqueleto, $27 \%$ nos músculos, 6 - 7\% em outras células e uma quantidade muito reduzida, no espaço extracelular (Shils, 1999). Entretanto, a deficiência desse mineral em indivíduos sadios que consomem uma dieta balanceada é bastante rara, devido à sua abundância em alimentos de origem vegetal ou animal. As principais fontes são os cereais, como trigo, aveia e arroz e os seus farelos, as leguminosas, como o feijão, soja, ervilha seca, grão de bico, entre outras. As hortaliças, devido ao seu elevado conteúdo em clorofila, contribuem para compor a ingestão diária. Como exemplo, a ingestão de $100 \mathrm{~g}$ de espinafre disponibilizaria teoricamente aproximadamente $58 \mathrm{mg}$ de $\mathrm{Mg}^{2+}$ para serem absorvidos (Souci, Fachmann, 1995). Recomenda-se a ingestão diária de $400 \mathrm{mg} \mathrm{Mg}{ }^{2+}$ para indivíduos do sexo masculino, entre 31 a 50 anos de idade, enquanto mulheres da mesma faixa etária necessitam de 310 $\mathrm{mg} / \mathrm{dia}$ (Institute of Medicine, Food and Nutrition Board, 1997).

Quanto à clivagem do fitol, parece pouco provável que esta ocorra durante a fase de digestão gástrica ou no intestino delgado. As condições não são suficientemente ácidas para promover a hidrólise da ligação éster e o organismo animal não possui uma enzima que possa catalizar essa reação. Assim, o aparecimento de feoforbídeos nas fezes pode ser atribuído, provavelmente, ao metabolismo bacteriano do intestino grosso.

Explica-se, assim, com certa facilidade a excreção de feofitina (sem $\mathrm{Mg}^{2+}$ ) o feoforbideo $\boldsymbol{a}$ (sem fitol) e em alguns casos o aparecimento do pirofeoforbídeo $\boldsymbol{a}$ (sem o grupo metilcarboxila). Teoricamente, no organismo animal, estas três substâncias poderiam dar origem a inúme- 
ros derivados, identificados a partir de reações químicas conduzidas em laboratório, mas as estruturas químicas são distintas daquelas descritas para os metabólitos produzidos durante a senescência de vegetais (Hynninen, 1991). As reações de degradação subseqüentes, ao contrário do que acontece nas células vivas em vegetais senescentes, não seguem uma via de degradação padronizada, devido à variedade de condições digestivas e de tratamento ao qual o alimento foi submetido antes da sua ingestão.

Surgem agora duas perguntas importantes: os metabólitos podem exercer algum efeito biológico importante no próprio intestino ou após uma suposta absorção? Os metabólitos oriundos da degradação da clorofila podem ser absorvidos e atingir a circulação sangüínea?

\section{Atividades antioxidante, antimutagênica e quimiopreventiva}

As pesquisas relativas às atividades antioxidante $\mathrm{e}$ quimiopreventiva da clorofila e de seus derivados tiveram impulso a partir da década de 1980. Ao contrário do que está sendo proposto atualmente, em relação à possível atividade antioxidante, tanto a clorofila, quanto a feofitina e o feoforbídeo apresentam atividade pró-oxidante em óleos e gorduras comestíveis, com evidente prejuízo sobre a qualidade do óleo. O conteúdo de clorofila e seus derivados é um parâmetro de qualidade, devendo essas substâncias ser removidas durante o processo de refino dos óleos para aumentar a estabilidade oxidativa dos mesmos (Cenkowski, Jayas, 1993; Gomes et al., 2003; Levadoux, et al., 19887; Minguez-Mosquera et al., 1990; Tautorus, Low, 1993). Os resultados dessas pesquisas indicam que esses pigmentos promovem e catalisam a foto-oxidação do óleo quando expostos à luz, devido às características fotossensibilizantes do anel porfirina dessas moléculas, o que facilita a formação de oxigênio singlete, dando início, assim, ao processo de autoxidação.

$\mathrm{O}$ fato de a feofitina demonstrar atividade próoxidante até superior à da clorofila revela que o magnésio, apesar de ser considerado um catalisador do processo da autoxidação, não interfere na velocidade da reação. Fato semelhante ocorre com o feoforbídeo, que não possui o fitol. Acredita-se, portanto, que a atividade pró-oxidante esteja relacionada diretamente com o anel porfirina e não dependa da estrutura lateral da molécula (Endo et al., 1984; Tautorus, Low, 1993; Usuki et al., 1984).

Diante disso, e apesar da coerência dos resultados apresentados até aqui, outros estudos mostram atividade antioxidante da clorofila e de seus derivados sobre a oxidação de óleos, quando a incubação ocorre no escuro. O mecanismo para explicar a atividade antioxidante ainda não foi elucidado, mas supõe-se que a molécula da clorofila ou de seus derivados atue como um seqüestrador de radicais livres, ou de radicais peroxila, inibindo o processo de autoxidação de óleos comestíveis (Endo et al., 1984, 1985).

Ainda não foi esclarecido até que ponto essa atividade antioxidante, verificada no escuro, ocorreria com a clorofila existente em alimentos que não são mantidos protegidos da ação da luz, uma vez que ela é molécula fotossensível.

Outros estudos subseqüentes atestam atividade antioxidante tanto para a molécula de clorofila, como para derivados da clorofilina cúprica: a clorina $\mathrm{e}_{4} \mathrm{e}$ a clorina $\mathrm{e}_{6}$, apesar de ainda não existir uma explicação plausível para o mecanismo dessa atividade. Os testes de inibição da peroxidação lipídica em sistemas biológicos foram realizados utilizando modelos in vitro e testes químicos (Sakata et al., 1990; Sato et al., 1986). A clorofilina cúprica, como já mencionado anteriormente, é um derivado sintético da clorofila, comumente utilizado e aprovado em alguns países como aditivo nos alimentos, que confere coloração verde aos produtos aos quais é adicionado. Quimicamente tratase de molécula bastante estável, hidrossolúvel, diferenciando-se da clorofila pela substituição do átomo de Mg por um átomo de $\mathrm{Cu}$ e por não possuir o fitol.

$\mathrm{Na}$ última década os estudos se concentraram nos efeitos antimutagênicos e anticancerígenos da clorofila, uma vez que estes estão relacionados, freqüentemente, com a atividade antioxidante, embora por um mecanismo indireto.

Há alguns estudos que atribuem à clorofila e ao seu derivado sintético, a clorofilina cúprica, potente atividade antimutagênica (Chenormorsky et al., 1999; Dashwood, 1997; Dashwood et al., 1998; Negishi, Hayatsu, 1997; Odin, 1997).

Foi estabelecida, também, correlação positiva entre a concentração de clorofila em diversos extratos vegetais e a sua capacidade de inibir mutações pelo teste clássico de Ames (Lai et al., 1980). Tal correlação foi encontrada também nos vegetais que fazem parte dos hábitos alimentares da população coreana (Kimm et al., 1982). A clorofila foi testada, também, contra os condensados de fumaça de cigarro e diversas outras substâncias carcinógenas, tendo mostrado atividade inibitória variável (Gentile \& Gentile, 1991; Terwel \& Van der Hoeven, 1985).

Foi confirmado ainda que tanto a clorofila natural isolada de algas, como a feofitina e o feoforbídeo apresentam atividade antimutagênica, sugerindo que as propriedades biológicas estejam relacionadas com o macrociclo ou com substâncias derivadas deste, tais como as clorinas, e não com as cadeias laterais (Chenormorsky et al., 1999; Okai, Higashi-Okai, 1997). 
Vários são os mecanismos de proteção que impedem que o organismo animal inicie um processo de multiplicação desordenada de suas células. Dentre estes, a complexação de substâncias com atividade antimutagênica ou anticarcinogênica com outros compostos que causariam dano ao DNA reduz a biodisponibilidade do carcinógeno (Breinholt et al., 1995b). Essa atividade poderia ser exercida no lúmen do trato gastro-intestinal, ou então em órgãos internos do organismo animal, desde que a substância quimiopreventiva tenha sido absorvida para a corrente sanguínea.

Outra teoria bastante conhecida para explicar a atividade antimutagênica está relacionada com o "reparo" do DNA, danificado por substâncias mutagênicas por intermédio de ligações cruzadas. Muitos agentes associados ao processo de ligação cruzada com o DNA são produzidos durante o metabolismo oxidativo e correspondem aos radicais livres do oxigênio. Um dos efeitos dos radicais livres é o aumento da taxa de peroxidação lipídica com prejuízo na atividade das enzimas mitocondriais e com dano das membranas plasmáticas. Paralelamente, as reações de peroxidação podem ser responsabilizadas pela formação de substâncias como os malonaldeídos, que participam diretamente do processo de ligações cruzadas com o DNA. A formação dos radicais pode ser diminuída por substâncias antioxidantes, tais como vitaminas $\mathrm{E}$ ou $\mathrm{C}$, carotenóides e por substâncias fenólicas e polifenólicas, amplamente distribuídas nos vegetais.

As substâncias químicas antimutagênicas poderiam atuar por um mecanismo relacionado com a reparação do DNA, removendo a substância que causou a alteração do DNA, ou preventivamente, por uma ação antioxidante, de forma a impedir o dano ao DNA. Negishi et al. (1989) já haviam evidenciado a atividade antimutagênica da clorofila cúprica contra Trp-P-2 em Drosophila, sugerindo que a atividade inibitória poderia estar relacionada com a formação de complexo entre a clorofilina e a amina heterocíclica.

Baseado nesses mecanismos já estabelecidos, pesquisas lideradas por Bailey (Breinholt et al., $1995 \mathrm{a}, \mathrm{b}$; Dashwood et al., 1991; Harttig, Bailey, 1998) evidenciaram que a clorofila, a feofitina e a clorofilina cúprica são fortes inibidores da formação de adutos de substâncias carcinogênicas (aflatoxina B1 e dibenzo[a,l]pireno) com o DNA, em testes in vitro. A formação de complexos com o DNA representa o primeiro passo para a alteração da molécula do DNA, ativando-a e preparando-a para a replicação. Aventa-se a hipótese de que o mecanismo de inibição proporcionado pela clorofilina se baseia na complexação não covalente dessa molécula com a aflatoxina B1, numa estequiometria de aproximadamen- te $1: 1$, tornando a aflatoxina indisponível para formar adutos com o DNA, o que explicaria, então, a sua atividade anticarcinogênica. Contudo, foi observado pelos pesquisadores que a proteção contra a hepatocarcinogênese não pode ser atribuída exclusivamente à formação de adutos; a incubação de clorofilina com aflatoxina foi responsável por apenas $40-50 \%$ da redução da resposta tumoral. Algum outro mecanismo celular parece contribuir com a atividade protetora.

In vivo, os mesmos pesquisadores empregaram um modelo de estudo com trutas e avaliaram a inibição de formação de adutos hepáticos entre os carcinógenos e o DNA, bem como a incidência do processo de iniciação da carcinogênese nesses animais (Breinholt et al., 1995a; Dashwood et al., 1991; Harttig, Bailey, 1998).

A inibição da carcinogênese parece ser dose-dependente e a clorofilina cúprica em solução concentrada, administrada a trutas por sonda, foi mais efetiva do que a mesma quantidade de clorofila quando incorporada à dieta e administrada por sonda em dose única, embora em ambos os casos houvesse dependência da dose administrada. Estes resultados indicam que o efeito protetor fornecido pela solução pura, claramente superestima o efeito in vivo. O mecanismo parece ser ao menos parcialmente relacionado com a formação de complexo com a substância carcinogênica (Breinholt et al., 1995a). Com base no conjunto de resultados obtidos, os pesquisadores sugerem que a presença de clorofila na alimentação de peixes pode representar um importante fator anticarcinogênico.

Contudo, é necessário ter cautela ao extrapolar os dados obtidos em peixes para a nutrição humana. Os peixes têm um segmento intestinal especializado na absorção e transporte de macromoléculas intactas em grande quantidade, o que não ocorre em mamíferos (HernandezBlazquez, Silva, 1998; Nachi et al., 1998). O processo de absorção em mamíferos é muito mais seletivo, não permitindo o transporte de grandes volumes de moléculas grandes intactas, como é o caso da clorofila, que possui um peso molecular ao redor de 890 daltons (Auricchio et al., 1995). Fica, assim, comprometida qualquer afirmação relativa à eficácia da clorofila na prevenção de doenças em que é exigida a absorção prévia dessa molécula visto que os estudos em peixes não são um bom modelo para absorção intestinal em mamíferos.

\section{Digestão e absorção da clorofila}

Embora se tenha divulgado muito os efeitos benéficos potenciais da clorofila e de alguns dos seus derivados, praticamente nada se conhece sobre a absorção e metabolização do anel porfirínico em humanos. Estes es- 
tudos não são recentes - já em 1933 afirmava-se que a absorção da clorofila era negligenciável e outros trabalhos se seguiram confirmando esses primeiros achados (Baxter, 1968; Brugsch, Sheard, 1938; Fischer, Hendschel, 1933). O problema é que a molécula da clorofila é extremamente suscetível a reações químicas, tais como a perda do átomo de $\mathrm{Mg}$, a remoção do fitol, oxidação e fotoxidação, de modo que a instabilidade da molécula e o elevado custo da clorofila purificada tornam os ensaios em modelos com animais praticamente proibitivos.

Recentemente, Ferruzzi et al. $(2001,2002)$ empregaram um sistema in vitro e, além de simular as fases da digestão gástrica e intestinal, estudaram a absorção intestinal, utilizando como modelo, células intestinais humanas da linhagem Caco-2. Essas células exibem características semelhantes às dos enterócitos e podem ser empregadas para a absorção de nutrientes. Esses autores comprovaram que havia acúmulo de clorofilina cúprica em células intestinais humanas Caco-2, sugerindo haver transporte ativo e passivo através dessas células. Contudo, testes comparativos evidenciaram que compostos carotenóides eram acumulados no interior das células Caco-2 entre 20-40\%, enquanto a clorofila atingia apenas 5-10\%. Observou-se, ainda, que o efluxo apical era significativamente maior do que o efluxo basolateral.

Estes resultados foram os primeiros a demonstrar que poderia haver absorção da clorofila, embora bastante reduzida, por células intestinais humanas.

O fitol é parte integrante da clorofila e corresponde quimicamente a um álcool alifático ramificado de cadeia longa $\left(\mathrm{C}_{20} \mathrm{H}_{40} \mathrm{O}\right)$, ligado à molécula por uma ligação éster. Uma vez que essa ligação pode ser quebrada em algumas situações, pela clorofilase ou durante o processamento dos vegetais, o fitol, assim liberado, pode então ser absorvido pelo intestino e posteriormente convertido para ácido fitânico, um ácido graxo ainda pouco conhecido (ácido 3,7,11,15-tetrametilexadecanóico), mas de importantes efeitos biológicos, que passaremos a descrever.

A maior fonte de ácido fitânico no organismo humano não provém da clorofila, mas, sim, da ingestão de carnes de ruminantes, de gordura animal, de produtos derivados do leite, ou de pescados. Observou-se em estudos experimentais com ruminantes e peixes que a administração de fitol resulta no acúmulo de ácido fitânico em tecidos adiposos e aventa-se a hipótese de que este seja oriundo da metabolização do fitol por bactérias presentes no rúmen de bovinos e outros ruminantes que se alimentam de vegetais. Nos peixes, a sua presença é devida à ingestão de algas verdes e à absorção intestinal do fitol por um processo não seletivo. Na Figura 3 observa-se a estrutura química do fitol e do ácido fitânico.

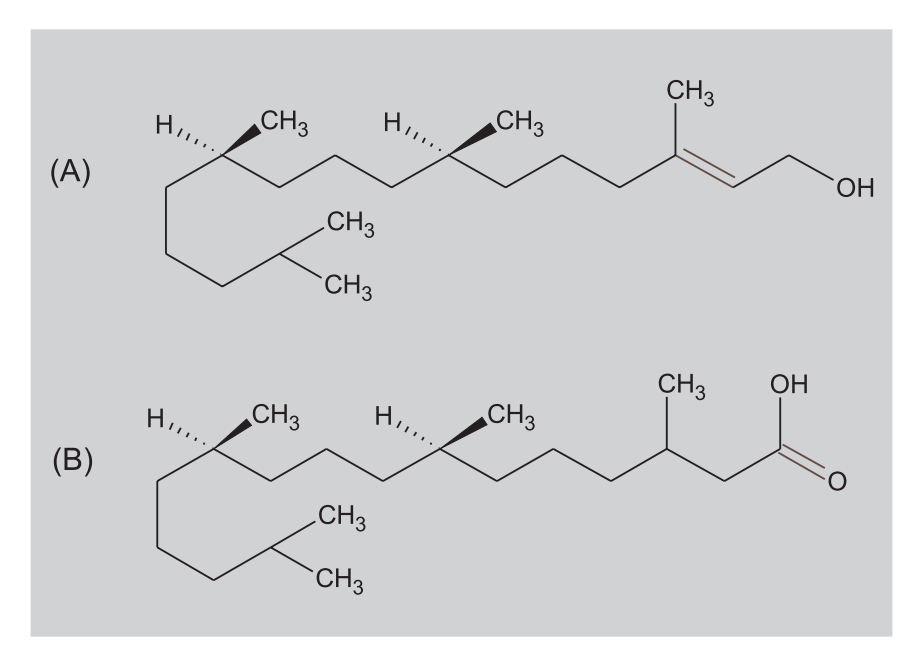

FIGURA 3 - Estrutura química do fitol (A) e do ácido fitânico (B).

Em humanos, o ácido fitânico provindo da alimentação é metabolizado prontamente por via enzimática por intermédio da ação da fitanoil-CoA hidroxilase e é detectado apenas em quantidades mínimas no plasma de indivíduos normais. Uma refeição normal pode conter até 50100 mg de ácido fitânico (Steinberg, 1995).

Entretanto, indivíduos com uma desordem metabólica dos lipídeos, de caráter recessivo, denominada de "Síndrome de Refsum", descrita inicialmente em 1946 por um neurologista sueco, são incapazes de metabolizar o ácido fitânico e acumulam quantidades muito elevadas desse ácido graxo no sangue e em diversos órgãos, tais como fígado, rins e outros. Nesses casos, o ácido fitânico pode atingir entre 5 a 30\% dos ácidos graxos totais presentes (Steinberg,1995; Verhoefen et al., 1998). Essa desordem, felizmente bastante rara, caracteriza-se por degeneração progressiva da visão (retinite pigmentosa), polineuropatia periférica e falta de coordenação muscular (ataxia cerebelar), entre outros sintomas graves. A causa é a deficiência da fitanoil-CoA-hidroxilase, que catalisa o primeiro passo da metabolização do ácido fitânico, que consiste na remoção de um carbono por uma reação de aoxidação (Jansen et al., 1997). Eldjarn e cols., em 1966, reportaram que uma dieta restrita em fitol, ácido fitânico ou clorofila pode atenuar a gravidade dos sintomas da doença de Refsum e ter resultados positivos sobre a redução dos níveis desse ácido graxo, conferindo melhora do quadro clínico da doença. Essa constatação resultou, naquela época, na exclusão de qualquer vegetal verde da alimentação dos pacientes com doença de Refsum. Esta limitação de ingerir vegetais verdes vigorou até poucos anos atrás e só foi revista com as novas descobertas relativas à degradação da clorofila no organismo animal. Aparentemente, não existem quantidades significativas de 
fitol livre nos alimentos frescos e há razões para se acreditar que a liberação do fitol a partir da degradação da clorofila no trato gastrointestinal é pouco eficiente, como já comentado anteriormente (Peisker et al., 1989). Assim, a partir de 1993, o Hospital Westminster de Londres publicou uma cartilha, atenuando a restrição e permitindo aos pacientes com a "Síndrome de Refsum a ingestão de vegetais verdes frescos", uma vez que o organismo parece não absorver o fitol ligado covalentemente à clorofila (Dietary treatment of Refsum's disease, 2002). Acreditase que o ácido fitânico no plasma seja proveniente predominantemente da absorção deste ácido presente na dieta, uma vez que o organismo humano não é capaz de sintetizar essa molécula.

Em que pesem as dúvidas, é importante refletir e obter maiores conhecimentos sobre a liberação do fitol durante o armazenamento, cozimento ou processamento de vegetais verdes. $\mathrm{O}$ fitol poderia ser liberado tanto por ação enzimática, pela clorofilase, como já mencionado anteriormente, como durante o cozimento, embora seja difícil avaliar a quantidade de fitol liberada, que poderá depender do tempo/temperatura de cocção, ou de outras variáveis.

Mas, de qualquer forma, é importante mencionar que o fitol é uma molécula capaz de ser absorvida pelo organismo humano e desempenhar diversas funções biológicas.

De fato, o ácido fitânico adquiriu recentemente importância a partir da descoberta de algumas atividades biológicas que lhe vêm sendo atribuídas. Uma das hipóteses está relacionada com a ativação do sistema termogênico de adipócitos marrons, promovendo aumento na transcrição e expressão do gene para a proteína UCP-1 (uncoupling protein 1), que atua desacoplando a fosforilação oxidativa mitocondrial (Schluter et al., 2002). O mecanismo de ação envolve a ligação do ácido fítânico ao ácido retinóico, que reconhecidamente é um ativador da transcrição do gene UCP-1 (Lemotte et al., 1996). Ademais, atribui-se ao fitol e ao ácido fitânico a ação preventiva da teratogênese em camundongos, causada pela ingestão excessiva de vitamina A. Estudos farmacocinéticos revelaram que a administração concomitante de fitol e retinol reduziu os níveis plasmáticos do retinol e de seus ésteres, bem como do ácido retinóico all-trans, nos estudos com camundongos não-prenhes, bloqueando, portanto, o efeito teratogênico da vitamina A (Arnhold et al., 2002). Apesar de essas proposições oferecerem enorme campo de investigação, mais estudos serão necessários e certamente um dos pontos que merece ser aprofundado é quanto à importância da dieta na modulação desses efeitos biológicos.

\section{CONSIDERAÇÕES FINAIS}

Várias são as afirmações veiculadas pelos meios de comunicação que procuram atribuir à ingestão de clorofila os mais diferentes benefícios à saúde humana. Algumas enfatizam as doenças do coração, outras, as doenças tumorais e há quem afirme que a clorofila evita queda de cabelo, promove a desinfecção interna do organismo, auxilia no tratamento da hipertensão, na proteção hepática, no diabetes e inúmeros outros efeitos, que de uma maneira ou outra estariam relacionados com o "Bem-Estar" do indivíduo.

Apesar da variedade de ações apontadas, essas teorias falham em encontrar comprovação científica que as sustentem e muitas estão realmente longe de serem comprovadas.

De qualquer forma, para alguns autores, o núcleo tetrapirrólico da clorofila, da feofitina ou mesmo de alguns derivados dessa molécula, seria capaz de exercer uma atividade antioxidante e quimiopreventiva. Em ambos os casos, a nosso ver, esse efeito se daria apenas no lúmen intestinal, uma vez que não foi possível localizar estudos que comprovassem a absorção intestinal do núcleo da clorofila em quantidades suficientes que pudessem justificar algum impacto sobre processos bioquímicos. E ainda assim, a hipótese da atividade antioxidante deverá ser melhor estudada, uma vez que a clorofila exerce, quando exposta à luz, efeito pró-oxidante. A atribuição de atividades quimiopreventivas, apesar do enorme interesse que suscita entre os pesquisadores, ainda fica restrita ao trato gastrointestinal e a explicação mais convincente, até o momento, favorece a teoria da complexação com a substância carcinogênica, à semelhança da fração fibra solúvel e de muitas outras substâncias fitoquímicas presentes em dietas vegetais. Estudos que comprovam a inibição da carcinogênese hepática foram realizados em peixes e os resultados não podem ser extrapolados para humanos, em virtude da diversidade do processo absortivo intestinal. $\mathrm{O}$ átomo de magnésio, importante para o indíviduo sob ponto de vista bioquímico, é liberado da clorofila em diversas condições de armazenamento e/ou processamento do alimento e até durante a passagem pelo trato gastrointestinal, tornando-se disponível para a absorção. Entretanto, devido à abundância desse mineral nos alimentos tanto vegetais, como animais, é bastante raro um quadro de deficiência em indivíduos sadios e com alimentação balanceada.

Por outro lado, o fitol, que é parte integrante da molécula de clorofila, parece ser responsável por efeitos biológicos importantes, tais como atividade termogênica em mamíferos e atividade inibidora sobre efeitos teratogênicos do retinol, descobertos recentemente. Por 
outro lado, muitas pesquisas devem ser realizadas, uma vez que não há evidências de que o fitol seja liberado da clorofila durante o processo digestivo. Especula-se que o processamento dos vegetais, a princípio, poderia acarretar a liberação do fitol, que então se tornaria disponível para exercer os efeitos biológicos mencionados.

\section{ABSTRACT}

\section{The role of chlorophyll in human feeding: a review}

The eventual physiological beneficial effects of chlorophyll present in foods have been raised questions and caused some doubts among consumers. Disclosing reports from mass media ascribing to the molecule of chlorophyll manifold therapeutic effects, nearby miraculous, oppose to the lack of full approval by the academic community. This article provides an overview about this topic and points out recent scientific findings regarding this subject. Considering that degradation products could be quite different during senescence, post-harvest and food processing procedures, as well as during the digestion process, each case in particular has been discussed. Also, the importance of molecular modifications has been highlighted in view of the potential antioxidant, antimutagenic and chemopreventive properties. Unfortunately, the scientific evidences are still not strong enough to support consistent health protecting roles for chlorophyll. Although, diversified mechanisms have been pointed out to explain the potential health benefits, some of them are still far from confirmation on human beings and strategies for further investigations should be incentivated. In addition, studies related to the biological function of phytol should be performed as phytol absorbed into the bloodstream in its free form has been found to play important functions no only on the metabolism of lipids but on the modulation of metabolic processes as well.

UNITERMS: Chlorophyll. Degradation. Absorption. Biological effects

\section{AGRADECIMENTOS}

À FAPESP, pelo suporte financeiro para as pesquisas relativas aos mecanismos químicos e bioquímicos de degradação da clorofila, que vêm sendo desenvolvidas no Depto. de Alimentos e Nutrição Experimental, e às valiosas discussões técnicas com o Prof. Assoc. Francisco J. Hernandez Blazquez, Dra. Patrícia Sinnecker e Márcio Henrique Terra.

\section{REFERÊNCIAS BIBLIOGRÁFICAS}

AMIR-SHAPIRA, D.; GOLDSCHMIDT, E.E.; ALTMAN, A. Chlorophyll catabolism in senescing plant tissues: in vivo breakdown intermediates suggest different degradative pathways for citrus fruit and parsley leaves. Proc. Natl. Acad. Sci. U. S. A., Washington, v.84, p.19011905, 1987.

ARAI, S. Global view on functional foods: Asian perspectives. Br. J. Nutr., Wallingford, v.88, n.2, p.S139S143, 2002.

ARAI S. Studies on functional foods in Japan, State of the Art. Biosci. Biotechnol. Biochem., Tokyo, v.60, n.1, p.915, 1996.

ARNHOLD, T.; MOHAMED, M.A.; ELMAZAR, N.H. Prevention of vitamin A teratogenesis by phytol of phytanic acid results from reduced metabolism of retinol to the teratogenic metabolite, all-trans-retinoic acid. Toxicol. Sci., Cary, v.66, p.274-282, 2002.

AURICCHIO, S.; FERGUSON, A.; TRONCONE, R. Mucosal immunity and the gut epithelium: interactions in health and disease. Basel: Karger, 1995. 188p. (Dynamic nutrition research, v.4 ) (Symposium on Mucosal Immunity and the Gut Epithelium: Interactions in Health and Disease, held in Capri on April 22-23, 1994).

BAXTER, J.H. Absorption of phytol in normal men and in patients with Refsum's disease. J. Lipid. Res., Bethesda, v.9, p.636-641, 1968.

BOTTING, K.J.; YOUNG, M.M.; PEARSON, A.E.; HARRIS, P.J.; FERGUSON, L.R. Antimutagens in food plants eaten by Polynesians, micronutrients, phytochemicals and protection against bacterial mutagenicity of the heterocyclic amine 2-amino-3methylimidazol[4,5-f]quinoline. Food Chem. Toxicol., Amsterdam, v.37, p.95-103, 1999.

BREINHOLT, V.; HENDRICKS, J.; PEREIRA, C.; ARBOGAST, D.; BAILEY, G. Dietary chlorophyllin is a potent inhibitor of aflatoxin $\mathrm{B} 1$ hepatocarcinogenesis in rainbow trout. Cancer. Res., Birmingham, v.55, n.1, p.57$62,1995 \mathrm{a}$. 
BREINHOLT, V.; SCHIMERLIK, M.; DASHWOOD, R.; BAILEY, G. Mechanism of chlorophyllin anticarcinogenesis against aflatoxin $\mathrm{B}_{1}$, complex formation with the carcinogen. Chem. Res. Toxicol., Columbus, v.8, p.506-514, 1995 b.

BRUGSCH, J.T.; SHEARD, C. Chlorophyll, determination and quantitative estimation of decomposition of chlorophyll in the human body. J. Lab. Clin. Med., Saint Louis, v.24, p.230-234, 1938.

CENKOWSKI, S.; JAYAS, D.S. Potential of in-field and low-temperature drying for reducing chlorophyll contents in canola (Brassica napus L). J. Sci. Food Agric., Bognor Regis, v.63, p.377-383, 1993.

CHERNORMORSKY, S.; SEGELMAN, A.; PORETZ, R.D. Effect of dietary chlorophyll derivatives on mutagenesis and tumor cell growth. Teratog., Carcinog., Mutagen., NewYork, v.19, p.313-322, 1999.

CURTY, C.; ENGEL, N.; GOSSAUER, A. Evidence for a monooxygenase-catalyzed primary process in the catabolism of chlorophyll. FEBS Lett., Amsterdam, v.364, p.41-44, 1995.

DASHWOOD, R. The importance of using pure chemicals in (anti)-mutagenicity studies, chlorophyllin as a case in point. Mutat. Res., Amsterdam, v.381, p.283-286, 1997.

DASHWOOD, R.H.; BREINHOLT, V.; BAILEY, G.S. Chemopreventive properties of chlorophyllin, inhibition of aflatoxin $\mathrm{B}_{1}, \mathrm{n} . \mathrm{AFB}_{1}$ )-DNA binding in vivo and antimutagenic activity against $\mathrm{AFB}_{1}$ and two heterocyclic amines in the Salmonella mutagenicity assay. Carcinogenesis, Oxford, v.12, n.5, p.939-942, 1991.

DASHWOOD, R.H.; NEGISHI, T.; HAYATSU, H.; BREINHOLT, V.; HENDRICKS, J.; BAILEY, G. Chemopreventive properties of chlorophylls toward aflatoxin B1, a review of the antimutagenicity and anticarcinogenicity data in rainbow trout. Mutat. Res., Amsterdam, v.399, p.245-253, 1998.

DIET TREATMENT OF REFSUM'S DISEASE. Disponível em: http//www.alphalink.com.au/ dijon/ index3.htm Acesso em: 17 abr. 2003.
ELDJARN, L.; TRY, K.; STOKKE, O.; MUNTHEKA, A.W.; REFSUM, S.; STEINBERG, D.; AVIGAN, J.; MIZE, C. Dietary effects on serum-phytanic-acid levels and on clinical manifestations in heredopathia atactica polyneuritiformis. Lancet., London, v.1, n.7439, p.691693, 1966.

ENDO, Y.; USUKI, R.; KANEDA, T. Antioxidant effects of chlorophyll and pheophytin on the autoxidation of oils in the dark. II. The mechanism of antioxidative action of chlorophyll. J. Am. Oil Chem. Soc., Champaign, v.62, n.9, p.1387-1390, 1985.

ENDO, Y.; USUKI, R.; KANEDA, T. Prooxidant activities of chlorophylls and their decomposition products on the photooxidation of methyl linoleate. J. Am. Oil Chem. Soc., Champaign, v.61, n.4, p.781-784, 1984.

FERRUZZI, M.G.; FAILLA, M.L.; SCHWARTZ, S.J. Assessment of degradation and intestinal cell uptake of carotenoids and chlorophyll derivatives from spinach puree using an in vitro digestion and Caco-2 human cell model. J. Agric. Food Chem., Columbus, v.49, p.20822089, 2001.

FERRUZZI, M.G.; FAILLA, M.L.; SCHWARTZ, S.J. Sodium copper chlorophyllin, in vitro digestive stability and accumulation by Caco-2 human intestinal cells. $J$. Agric. Food Chem., Columbus, v.50, p.2173-2179, 2002.

FISCHBACH, H. Microdeterminations for organically combined metal in pigment of okra. J. Assoc. Off. Agric. Chem., Baltimore, v.26, p.139-143, 1943.

FISHER, H.; HENDSCHEL, A. Isolation of chlorophyll derivatives from the feces of elephants and human beings. Z. Physiol. Chem., Strassburg, v.216, p.56-59, 1933.

FUNAMOTO, Y.; YAMAUCHI, N.; SHIGENAGA, T.; SHIGUIO, M. Effects of heat treatment on chlorophyll degrading enzymes in stored brocoli (Brassica oleracea L.). Postharvest. Biol. Technol., Amsterdam, v.24, p.163170, 2002.

GAUTHIER-JAQUES, A.; BORTLIK, K.; HAU, J.; FAY, L.B. Improved method to track chlorophyll degradation. J. Agric. Food Chem., Columbus, v.49, p.1117-1122, 2001. 
GENTILE, J.M.; GENTILE, G.J. The metabolic activation of 4-nitro-o-phenylenediamine by chlorophyllcontaining plant extracts, the relationship between mutagenicity and antimutagenicity. Mutat. Res., Amsterdam, v.250, p.79-86, 1991.

GOMES, M.S.O.; SINNECKER, P.; TANAKA, R.T.; LANFER-MARQUEZ, U.M. Effect of harvesting and drying conditions on chlorophyll levels of soybean (Glycine max L. Merr). J. Agric. Food Chem., Columbus, v.51, p.1634-1639, 2003.

GORDON, M.H. Dietary antioxidants in disease prevention. Nat. Prod. Rep., Letchworth, v.13, n.4, p.265-273, 1996.

GROSS, J. Pigments in vegetables, chlorophylls and carotenoids. New York: Van Nostrand Reinhold, 1991. $351 \mathrm{p}$.

HARTTIG, U.; BAILEY, G.S. Chemoprotection by natural chlorophylls in vivo, inhibition of dibenzo[a,1]pyreneDNA adducts in rainbow trout liver. Carcinogenesis, Oxford, v.19, n.7, p.1323-1326, 1998.

HEATON, J.W.; MARANGONI, A.G. Chlorophyll degradation in processed foods and senescent plant tissues. Trends Food Sci. Technol., Amsterdam, v.7, n.1, p.8-15, 1996.

HEATON, J.W.; LENCKI, R.W.; MARANGONI, A.G. Kinetic model for chlorophyll degradation in green tissue. J. Agric. Food Chem., Columbus, v.44, n.2, p.399402, 1996a.

HEATON, J.W.; YADA, R.Y.; MARANGONI, A.G. Discoloration of coleslaw is caused by chlorophyll degradation. J. Agric. Food Chem., Columbus, v.44, p.395-398, 1996b.

HENDRY, G.A.F.; HOUGHTON, J.D.; BROWN, S.B. Tansley review no.11. The degradation of chlorophyll, a biological enigma. New Phytol., Oxford, v.107, n.2, p.255-302, 1987.

HERNANDEZ-BLAZQUEZ, F.J.; SILVA, J.R.M.C. Absorption of macromolecular proteins by the rectal epithelium of the Antarctic fish Notothenia neglecta. Can. J. Zool., Ottawa, v.76, p.1247-1253, 1998.
HÖRTENSTEINER, S.; WÜTHRICH, K.L.; MATILE, P.; ONGANIA, K.H.; KRÄUTLER, B. The key step in chlorophyll breakdown in higher plants. Cleavage of pheophorbide a macrocycle by a monooxygenase. $J$. Biol. Chem., Birmingham, v.273, n.25, p.15335-15339, 1998.

HYNNINEN, P.H. Chemistry of chlorophylls, modifications. In: SCHEER H, ed. Chlorophylls. Boca Raton: CRC Press, 1991. p.145-209.

INSTITUTE OF MEDICINE. Food and Nutrition Board. Dietary reference intakes, calcium, phosphorus, magnesium, vitamin $D$, and fluoride. Washington: National Academy Press, 1997. p.190-249.

JANSEN, G.A.; WANDERS, R.J.A.; WATKINS, P.A.; MIHALIK, S.J. Phytanoyl-coenzyme A hydroxylase deficiency, the enzyme defect in Refsum's disease. $N$. Engl. J. Med., Waltham, v.337, n.2, p.111-134, 1997.

JOHNSON-FLANAGAN, A.M.; SPENCER, M.S. Chlorophyllase and peroxidase activity during degreening of maturing canola, (Brassica napus) and mustard (Brassica juncea) seed. Physiol. Plant., Copenhagen, v.97, p.353-359, 1996.

KEPHART, J.C. Chlorophyll derivatives, their chemistry, commercial preparations and uses. Econ. Bot., New York, v.9, p.3-38, 1955.

KIMM, S.W.; TCHAI, B.S.; PARK, S.; KANG, S. Antimutagenic activity of chlorophyll to direct-and indirect-acting mutagens and its contents in the vegetables. Korean J. Biochem., Seoul, v.14, p.1-7, 1982.

KITTS, D.D. An evaluation of the multiple effects of the antioxidant vitamins. Trends Food Sci. Technol., Amsterdam, v.8, p.198-203, 1997.

LABORDE, L.F.; VON ELBE, J.H. Chlorophyll degradation and zinc complex formation with chlorophyll derivatives in heated green vegetables. J. Agric. Food Chem., Columbus, v.42, p.1100-1103, 1994.

LAI, J.; BUTLER, M.A.; MATNEY, T. Antimutagenic activities of common vegetables and their chlorophyll content. Mutat. Res., Amsterdam, v.77, p.245-250, 1980. 
LAJOLO, F.M. Functional foods, Latin American perspectives. Br. J. Nutr., Wallingford, v.80, n.2, p.S145S150, 2002.

LANGMEIER, M.; GINSBURG, S.; MATILE, P. Chlorophyll breakdown in senescent leaves, demonstration of $\mathrm{Mg}$ dechelatase activity. Physiol. Plant., Copenhagen, v.89, p.347-353, 1993.

LEMOTTE, P.K.; KEIDEL, S.; APFEL, C.M. Phytanic acid is a retinoid $\mathrm{X}$ receptor ligand. Eur. J. Biochem., Oxford, v.236, p.328-333, 1996.

LEVADOUX, W.L.; KALMOKOFF, M.L.; PICKARD, M.D.; GROOFWASSINK, J.W.D. Pigment removal from canola oil using chlorophyllase. J. Am. Oil Chem. Soc., Champaign, v.64, n.1, p.139-144, 1987.

LIU, S.; MANSON, J.E.; LEE, I.M.; COLE, S.R.; HENNEKENS, C.H.; WILLETT, W.C.; BURING, J.E. Fruit and vegetable intake and risk of cardiovascular disease: the Women's Health Study. Am. J. Clin. Nutr., Bethesda, v.72, n.4, p.922-928, 2000.

MA, L.; DOLPHIN, D. The metabolites of dietary chlorophylls. Phytochemistry, Amsterdam, v.50, p.195202, 1999.

MAHARAJ, V.; SANKAT, C.K. Quality changes in dehydrated dasheen leaves, effects of blanching pretreatments and drying conditions. Food Res. Int., Amsterdam, v.29, p.563-568, 1996.

MARTÍNEZ, G.A.; CIVELLO, P.M.; CHAVES, A.L.; AÑON, M.C. Characterization of peroxidase-mediated chlorophyll bleaching in strawberry fruit. Phytochemistry, Amsterdam, v.58, p.379-387, 2001.

MATILE, P.; HÖRTENSTEINER, H.; THOMAS, H. Chlorophyll degradation. Annu Rev. Plant Physiol. Plant Mol. Biol., Palo Alto, v.50, p.67-95. 1999.

MÍNGUEZ-MOSQUERA, M.I.; GANDUL-ROJAS, B.; GARRIDO-FERNANDEZ，J.; GALLARDOGUERRERO, L. Pigments present in virgin oil. J. Am. Oil Chem. Soc., Champaign, v.67, n.3, p.192-196, 1990.

MÍNGUEZ-MOSQUERA, M.I.; GANDUL-ROJAS, B.; MINGUEZ-MOSQUERA, J. Mechanism and kinetics of the degradation of chlorophylls during the processing of green table olives. J. Agric. Food Chem., Columbus, v.42, p.1089-1095, 1994.
MINGUEZ-MOSQUERA, M.I.; GARRIDOFERNANDEZ, J.; GANDUL-ROJAS, B. Pigment changes in olives during fermentation and brine storage. J. Agric. Food Chem., Columbus, v.37, p.8-11, 1989.

NACHI, A.M.; HERNANDEZ-BLAZQUEZ, F.J.; BARBIERI, R.L.; LEITE, R.G.; FERRI, S.; PHAN, M.T. Intestinal histology of a detritivorous (iliophagous) fish Prochilodus scrofa (characiformes, prochilodontidae). Ann. Sci. Nat., Zool. Biol. Anim., Vineuil, v.19, n.2, p.8188, 1998.

NATIONAL RESEARCH COUNCIL. Committee on Comparative Toxicity of Naturally Occurring Carcinogens. Carcinogens and anticarcinogens in the human diet, a comparison of naturally occurring and synthetic substances. Washington: National Academy Press, 1996. 417p.

NEGISHI, T.; ARIMOTO, S.; NISHIZAKI, C.; HAYATSU, $\mathrm{H}$. Inhibitory effect of chlorophyll on the genotoxicity of 3-amino-1-methyl-5H-pyrido[4,3-b]indole (Trp-P-2). Carcinogenesis, Oxford, v.10, p.145-149, 1989.

NEGISHI, T.; RAI, H.; HAYATSU, H. Antigenotoxic activity of natural chlorophylls. Mutat. Res., Amsterdam, v.376, p.97-100, 1997.

OBERHUBER, M.; BERGHOLD, J.; MÜLLER, W.; HÖRTENSTEINER, S.; KRÄUTLER, B. Chlorophyll breakdown: on a nonfluorescent chlorophyll catabolite from spinach. Helv. Chim. Acta, Weinheim, v.84, p.2615$2627,2001$.

OBERHUBER, M.; KRÄUTLER, B. Breakdown of chlorophyll, electrochemical bilin reduction provides synthetic access to fluorescent chlorophyll catabolites. ChemBioChem, Weinheim, v.3, n.1, p.104-107, 2002.

ODIN, A.P. Antimutagenicity of the porphyrins and nonenzyme porphyrin-containing proteins. Mutat. Res., Amsterdam, v.387, p.55-68, 1997.

OKAI, Y.; HIGASHI-OKAI, K. Pheophytin $a$ is a potent suppressor against genotoxin-induced umu $\mathrm{C}$ gene expression in Salmonella typhymurium (TA 1535/pSK 1002). J. Sci. Food Agric., Bognor Regis, v.74, p.531$535,1997$.

PEISKER, C.; DUEGGELIN, T.; RENTSCH, D.; MATILE, P. Phytol and the breakdown of chlorophyll in senescent leaves. J. Plant Physiol., Jena, v.135, n.4, p.428-432, 1989. 
PHILIPPI, S.T.; LATTERZA, A.R.; CRUZ, A.T.R.; RIBEIRO, L.C. Pirâmide alimentar adaptada: guia para escolha dos alimentos. Rev. Nutr., Campinas, v.12, p.6571, 1999.

RAFTER, J.J. Scientific basis of biomarkers and benefits of functional foods for reduction of disease risk: cancer. $\mathrm{Br}$. Jr. Nutr., Wallingford, v.88, n.2, p.S219-S224, 2002.

ROCHA, T.; LEBERT, A.; MARTY-AUDOUIN, C. Effect of pretreatments and drying conditions on drying rate and colour retention of basil (Ocimum basilicum). Lebensm.Wiss. Technol., London, v.26, p.456-463, 1993.

RÜDIGER, W.; SCHOCH, S. Chlorophylls. In: GOODWIN, T.W., ed. Plant pigments. San Diego: Academic Press, 1988. p.1-53.

RÜDIGER, W. Chlorophyll metabolism, from outer space down to the molecular level. Phytochemistry, Amsterdam, v.46, n.7, p.1151-1167, 1997.

SAKATA, K.; YAMAMOTO, K.; ISHIKAWA, H.; YAGI, A.; ETOH, H.; INA, K. Chlorophyllone-A, a new pheophorbide-A related compound isolated from Ruditapes philippinarum as an antioxidative compound. Tetrahedron Lett., Oxford, v.31, n.8, p.1165-1168, 1990.

SATO, M.; FUJIMOTO, I.; SAKAI, T.; AIMOTO, T.; KIMURA, R.; MURATA, T. Effect of sodium copper Chlorophyllin on lipid-peroxidation. IX. On the antioxidative components in commercial preparations of sodium copper chlorophyllin. Chem. Pharm. Bull., Tokyo, v.34, n.6, p.2428-2434, 1986.

SCHLUTER, A.; BARBERA, M.J.; IGLESIAS, R.; GIRALT, M.; VILLAROYA, F. Phytanic acid, a novel activator of uncoupling protein-1 gene transcription and brown adipocyte differentiation. Biochem. J., London, v.362, p.61-69, 2002.

SCHWARTZ, S.J.; LORENZO, T.V. Chlorophyll in foods. Crit. Rev. Food Sci. Nutr., Fort Lauderdale, v.29, p.1-17, 1990.

SCHWARTZ, S.J.; LORENZO, T.V. Chlorophyll stability during continuous aseptic processing and storage. $J$. Food Sci., Chicago, v.56, p.1059-1062, 1991.
SHILS, M.E. Magnesium. In: SHILS, M.E.; OLSON, J.A.; SHIKE, M.; ROSS, A.C., eds. Modern nutrition in health and disease. 9.ed. Philadelphia: Lippincott Williams \& Wilkins, 1999. p.169-192.

SHIOI, Y.; MASUDA, T.; TAKAMIYA, K.; SHIMOKAWA, K. Breakdown of chlorophylls by soluble proteins extracted from leaves of Chenopodium album. J. Plant Physiol., Jena, v.145, p.416-421, 1995.

SOUCI, S.W.; FACHMANN, H.K. Food composition and nutrition tables. 5.ed. Stuttgart: Medpharm Scientific Publishers; Boca Raton: CRC Press, 1995. 1091p.

STEINBERG, D. Refsum disease. In: SCRIVER, C.R.; BEAUDET, A.L.; SLY, W.S.; VALLE, D., eds. The metabolic and molecular basis of inherited disease. 7.ed. New York: McGraw Hill, 1995. p.2351-2369.

STEINMETZ, K.A.; POTTER, J.D. Vegetables, fruit and cancer prevention: a review. J. Am. Diet Assoc., Chicago, v.96, p.1027-1039, 1996.

TAKAMIYA, K.; TSUCHIYA, T.; OHTA, H. Degradation pathways of chlorophylls, what has gene cloning revealed. Trends Plant. Sci., Oxford, v.5, n.10, p.426-431, 2000.

TAUTORUS, C.L.; LOW, N.H. Chemical aspects of chlorophyll breakdown products and their relevance to canola oil stability. J. Am. Oil Chem. Soc., Champaign, v.70, n.9, p.843-847, 1993.

TENG, S.S.; CHENG, B.H. Formation of pyrochlorophylls and their derivatives in spinach leaves during heating. Food Chem., Amsterdam, v.65, p.367-373, 1999.

TERWEL, L.; VAN DER HOEVEN, J.C.M. Antimutagenic activity of some naturally occurring compounds towards cigarette-smoke condensate and benzo[a]pyrene in the Salmonella/microsome assay. Mutat. Res., Amsterdam, v.152, n.1, p.1-4, 1985.

USUKI, R.; ENDO, Y.; KANEDA, T. Prooxidant activities of chlorophylls and pheophytins on the photooxidation of edible oils. Agric. Biol. Chem., Tokyo, v.48, n.4, p.991994, 1984.

VAN DUYN, M.A.; PIVONKA, E. Overview of the health benefits of fruit and vegetable consumption for the dietetics professional: selected literature. J. Am. Diet Assoc., Chicago, v.100, p.1511-1521, 2000. 
VERHAGEN, H.; ROMPELBERG, C.J.M.; STRUBE, M.; VAN POPPEL, G.; VAN BADEREN, P.J. Cancer prevention by dietary constituents in toxicological perspective. J. Environ. Pathol., Toxicol. Oncol., Congers, v.16, p.343-360, 1997.

VERHOEFEN, N.M.; WANDERS, R.J.; POLL, B.T.; SAUDUBRAY, J.M.; JACOBS, C. The metabolism of phytanic acid and pristanic acid in man: a review. $J$. Inherited Metab. Dis., Dordrecht, v.21, p.697-728, 1998.

VERSCHUREN, P.M. Functional foods, scientific and global perspectives. Br. J. Nutr., Wallingford, v.88, n.2, p.S125-S130, 2002.
WÜTHRICH, K.L.; BOVET, L.; HUNZIKER, P.E.; DONNISON, I.S.; HÖRTENSTEINER, S. Molecular cloning, functional expression and characterization of RCC reductase involved in chlorophyll catabolism. Plant J., Oxford, v.21, n.2, p.189-198, 2000.

YAMAUCHI, N.; WATADA, A.E. Regulated chlorophyll degradation in spinach leaves during storage. J. Am. Soc. Hortic. Sci., Alexandria, v.116, n.1, p.58-62, 1991.

YEN, G.C.; DUH, P.D.; HUNG, Y.L. Contributions of major components to the antimutagenic effect of Hsian-tsao (Mesona procumbens Hemsl). J. Agric. Food Chem., Columbus, v.49, p.5000-5004, 2001.

Recebido para publicação em 22 de abril de 2003. 